\title{
Systematic evaluation of oligodeoxynucleotide binding and hybridization to modified multi-walled carbon nanotubes
}

\author{
Anika Kaufmann ${ }^{1,4}$, Silke Hampel ${ }^{2}$, Christiane Rieger $^{3}$, David Kunhardt ${ }^{2}$, Darja Schendel ${ }^{3}$, Susanne Füssel ${ }^{3 *}$,
} Bernd Schwenzer ${ }^{1}$ and Kati Erdmann ${ }^{3}$

\begin{abstract}
Background: In addition to conventional chemotherapeutics, nucleic acid-based therapeutics like antisense oligodeoxynucleotides (AS-ODN) represent a novel approach for the treatment of bladder cancer (BCa). An efficient delivery of AS-ODN to the urothelium and then into cancer cells might be achieved by the local application of multiwalled carbon nanotubes (MWCNT). In the present study, pristine MWCNT and MWCNT functionalized with hydrophilic moieties were synthesized and then investigated regarding their physicochemical characteristics, dispersibility, biocompatibility, cellular uptake and mucoadhesive properties. Finally, their binding capacity for AS-ODN via hybridization to carrier strand oligodeoxynucleotides (CS-ODN), which were either non-covalently adsorbed or covalently bound to the different MWCNT types, was evaluated.
\end{abstract}

Results: Pristine MWCNT were successfully functionalized with hydrophilic moieties (MWCNT-OH, $\left.-\mathrm{COOH},-\mathrm{NH}_{2},-\mathrm{SH}\right)$, which led to an improved dispersibility and an enhanced dispersion stability. A viability assay revealed that MWCNT$\mathrm{OH}, \mathrm{MWCNT}-\mathrm{NH}_{2}$ and MWCNT-SH were most biocompatible. All MWCNT were internalized by BCa cells, whereupon the highest uptake was observed for MWCNT-OH with 40\% of the cells showing an engulfment. Furthermore, all types of MWCNT could adhere to the urothelium of explanted mouse bladders, but the amount of the covered urothelial area was with 2-7\% rather low. As indicated by fluorescence measurements, it was possible to attach CS-ODN by adsorption and covalent binding to functionalized MWCNT. Adsorption of CS-ODN to pristine MWCNT, MWCNT-COOH and MWCNT-NH $\mathrm{H}_{2}$ as well as covalent coupling to MWCNT-NH $\mathrm{N}_{2}$ and MWCNT-SH resulted in the best binding capacity and stability. Subsequently, therapeutic AS-ODN could be hybridized to and reversibly released from the CS-ODN coupled via both strategies to the functionalized MWCNT. The release of AS-ODN at experimental conditions ( $80^{\circ} \mathrm{C}$, buffer) was most effective from CS-ODN adsorbed to MWCNT-OH and MWCNT-NH 2 as well as from CS-ODN covalently attached to MWCNT-COOH, MWCNT-NH ${ }_{2}$ and MWCNT-SH. Furthermore, we could exemplarily demonstrate that AS-ODN could be released following hybridization to CS-ODN adsorbed to MWCNT-OH at physiological settings $\left(37^{\circ} \mathrm{C}\right.$, urine).

Conclusions: In conclusion, functionalized MWCNT might be used as nanotransporters in antisense therapy for the local treatment of BCa.

Keywords: Antisense oligodeoxynucleotides, Biocompatibility, Bladder cancer, Carbon nanotubes, Carrier strand, Functionalization, Hybridization, Mucoadhesion, Urothelium

\footnotetext{
*Correspondence: susanne.fuessel@mailbox.tu-dresden.de

${ }^{3}$ Department of Urology, University Hospital Carl Gustav Carus,

Technische Universität Dresden, Fetscherstraße 74, 01307 Dresden,

Germany

Full list of author information is available at the end of the article
} 


\section{Background}

Bladder cancer ( $\mathrm{BCa}$ ) is the most common malignancy of the urogenital system and the ninth most common cancer worldwide and thus poses a great challenge to the health care sector $[1,2]$. BCa treatment depends on tumor stage and prognosis of the patient. Superficial, non-muscleinvasive $\mathrm{BCa}$ is initially treated by transurethral resection of the bladder tumor followed by a local chemotherapy (mitomycin $\mathrm{C}$, epirubicin, doxorubicin) and/or immunotherapy (Bacillus Calmette-Guérin) in order to lower the probability of recurrence and progression [1]. This adjuvant therapy is directly instilled through a catheter into the bladder, which is ideally suitable for such an intravesical drug delivery due to its hollow structure [3]. Compared to a systemic drug administration, intravesical therapy ensures higher drug concentrations at the tumor site while minimizing systemic side effects [3].

However, the intravesical drug application has to overcome some obstacles. The most prominent drawback is the low dwell time of the therapeutics due to continuous urine production and flushing during voiding. Furthermore, poor adhesion of the drugs to the urothelium and deprived penetration into it result in a decreased absorption and lower effective concentration of the therapeutic. Consequently, repeated instillations via catheterizations are required, which is inconvenient for the patient and may cause inflammatory reactions, bladder irritation and infections [3]. Finally, failure of chemotherapy could be evoked by the up-regulation of genes associated with drug resistance, which in turn provide attractive targets for molecular therapy $[4,5]$. Complementary to conventional treatment options such as chemotherapy, surgery and radiation, therapeutic nucleic acids including antisense oligodeoxynucleotides (AS-ODN) and small interfering RNAs (siRNAs) have emerged as a promising strategy to modify the expression of such tumorrelated genes. In order to achieve an effective therapy, it is important to sufficiently deliver the genetic cargo to the tumor cells while evading clearance and degradation. Consequently, a wide variety of viral and non-viral gene therapy vectors have been developed and evaluated in the last years.

The development of innovative drug delivery systems combining a multifunctional therapy approach is necessary and of utmost interest. Particularly, carbon nanotubes (CNT) possess immense potential as nanocarriers for such biomedical applications due to their ability to be functionalized with various therapeutic agents [6-8]. For that matter, we have shown that multi-walled CNT (MWCNT) could be loaded with conventional chemotherapeutics and thus mediate anti-proliferative effects in various cancer cells $[9,10]$. The functionalization of CNT with AS-ODN or siRNAs represents another promising approach to create multifunctional nanocarriers and to sufficiently deliver genetic payload to the tumor site [6, 8]. We and others have previously shown that CNT can successfully be coupled with AS-ODN or ODN [11-14]. In our prior study, AS-ODN against the angiogenic growth factor VEGF were linked via adsorbed carrier strand oligodeoxynucleotides (CS-ODN) onto hydroxyl group-functionalized MWCNT (MWCNT-OH) [11].

In $\mathrm{BCa}$ it is necessary to transport the therapeutic agent to the cancer cells located in the bladder urothelium. Therefore, the gene therapy vector has to adhere to the bladder urothelium and release its genetic payload. Furthermore, it would be advantageous, if the aforementioned low dwell time of therapeutics inside the bladder could be increased. In addition to adhesion to the urothelium, cellular uptake and biocompatibility are important prerequisites for the effectiveness of nanocarriers in $\mathrm{BCa}$ treatment. We have previously demonstrated that various types of pristine MWCNT (p-MWCNT) can adhere to the urothelium of mouse bladders [15] and can be internalized by cancer cells $[11,16]$. Another important challenge that has to be addressed when using CNT for biomedical applications in vivo is their toxic, inflammatory and immunogenic potential. Due to their small size and structural resemblance to asbestos, CNT could evoke deleterious effects, whereupon MWCNT are generally less toxic than single-walled CNT (SWCNT) [7]. However, by the introduction of functional moieties to p-MWCNT their biocompatibility as well as dispersibility, cellular uptake and mucoadhesive properties might be further improved.

In the present study we modified p-MWCNT with different functional groups (MWCNT-OH, $-\mathrm{COOH},-\mathrm{NH}_{2}$, $-\mathrm{SH})$ followed by a comprehensive physicochemical characterization of the functionalized MWCNT including an evaluation of their dispersibility. Furthermore, the biocompatibility, cellular uptake and mucoadhesive properties of all MWCNT were examined. Then, we investigated their binding capacity for CS-ODN by using two different attachment strategies: non-covalent adsorption and covalent binding. Subsequently, the hybridization efficiency and the release of AS-ODN coupled to MWCNT-bound CS-ODN were evaluated at experimental and physiological conditions.

\section{Methods \\ Chemicals}

$\mathrm{HNO}_{3}, \mathrm{NaCl}$ and $\mathrm{NaOH}$ were obtained from VWR International $\mathrm{GmbH}$ (Darmstadt, Germany). 1-Ethyl3-(3-dimethylaminopropyl)carbodiimid (EDC), $N$-hydroxysuccinimid (NHS), 2-(N-morpholino)ethanesulfonic acid (MES), tetrahydrofuran (THF) and cysteamine were purchased from Sigma-Aldrich (Taufkirchen, Germany). 
3,4-dihydroxybenzaldehyde (DHBA), N,N-dimethylformamide (DMF), $\mathrm{H}_{2} \mathrm{SO}_{4}$, ethylenediamine, methanol and chloroform were acquired from Merck (Darmstadt, Germany). $N$-(tri(hydroxymethyl)methyl)glycin (tricine) was obtained from Alfa Aesar (Karlsruhe, Germany). Disuccinimidyl suberate (DSS) and $N, N^{\prime}$-dicyclohexylcarbodiimide (DCC) were from Thermo Fisher Scientific (Dreieich, Germany) and Interchim (Montluçon, France), respectively. The buffer ingredients $\mathrm{KH}_{2} \mathrm{PO}_{4}, \mathrm{~K}_{2} \mathrm{HPO}_{4} \cdot 3 \mathrm{H}_{2} \mathrm{O}, \mathrm{Na}_{2} \mathrm{HPO}_{4} \cdot 2$ $\mathrm{H}_{2} \mathrm{O}, \mathrm{NaHCO}_{3}$ and $\mathrm{C}_{2} \mathrm{H}_{3} \mathrm{NaO}_{2} \cdot 3 \mathrm{H}_{2} \mathrm{O}$ were purchased from Gruessing (Filsum, Germany). All buffers were prepared in distilled water and sterilized before use.

\section{Synthesis and characterization of functionalized MWCNT} p-MWCNT were synthesized by chemical vapor deposition as described previously $[15,17]$. The catalyst particles were removed by washing with $32.5 \%$ nitric acid, which also leads to some oxidation of the p-MWCNT. Following purification p-MWCNT were filtered, washed with deionized water and dried at $110{ }^{\circ} \mathrm{C}$ for several hours [17]. They are composed of individual filaments of graphene walls with an average outer diameter and length of 11 and $980 \mathrm{~nm}$, respectively [15]. To generate
MWCNT-OH, hydroxyl groups were attached to the surface by 1,3-dipolar cycloaddition with tricine and DHBA as reactants (Fig. 1) [11]. For synthesis of MWCNT$\mathrm{COOH}$ (Fig. 1), $200 \mathrm{mg}$ p-MWCNT were dispersed in $\mathrm{H}_{2} \mathrm{SO}_{4} / \mathrm{HNO}_{3}$ (3:1) for $3 \mathrm{~h}$ in a sonication bath, filtrated and washed with distilled $\mathrm{H}_{2} \mathrm{O}$ until the $\mathrm{pH}$ was neutral. The product MWCNT-COOH was dried overnight at $108{ }^{\circ} \mathrm{C}$. Synthesis of MWCNT-NH$H_{2}$ and MWCNT$\mathrm{SH}$ was performed as described by Jeong et al. with an extended reaction time (Fig. 1) [18]. Briefly, $10 \mathrm{mg}$ MWCNT-COOH and $10 \mathrm{mg}$ DCC were sonicated for $5 \mathrm{~min}$ in $2 \mathrm{ml}$ THF and stirred for $30 \mathrm{~min}$. The dispersion was filtrated and washed with THF and methanol. Thereafter, the activated MWCNT were dispersed in THF. To produce MWCNT-NH $\mathrm{N}_{2}$ and MWCNT-SH $4 \mathrm{ml}$ ethylenediamine in $2 \mathrm{ml}$ THF and $25 \mathrm{mg}$ cysteamine in $4 \mathrm{ml} \mathrm{THF}$, respectively, were added and the mixtures were stirred for $2.5 \mathrm{~h}$. Afterwards, the dispersions were filtrated and washed with THF. The final products were dried for $72 \mathrm{~h}$ at $40{ }^{\circ} \mathrm{C}$.

Finally, pristine and functionalized MWCNT were analyzed by X-ray photoelectron spectroscopy (XPS), thermogravimetric analysis (TGA), Fourier transform

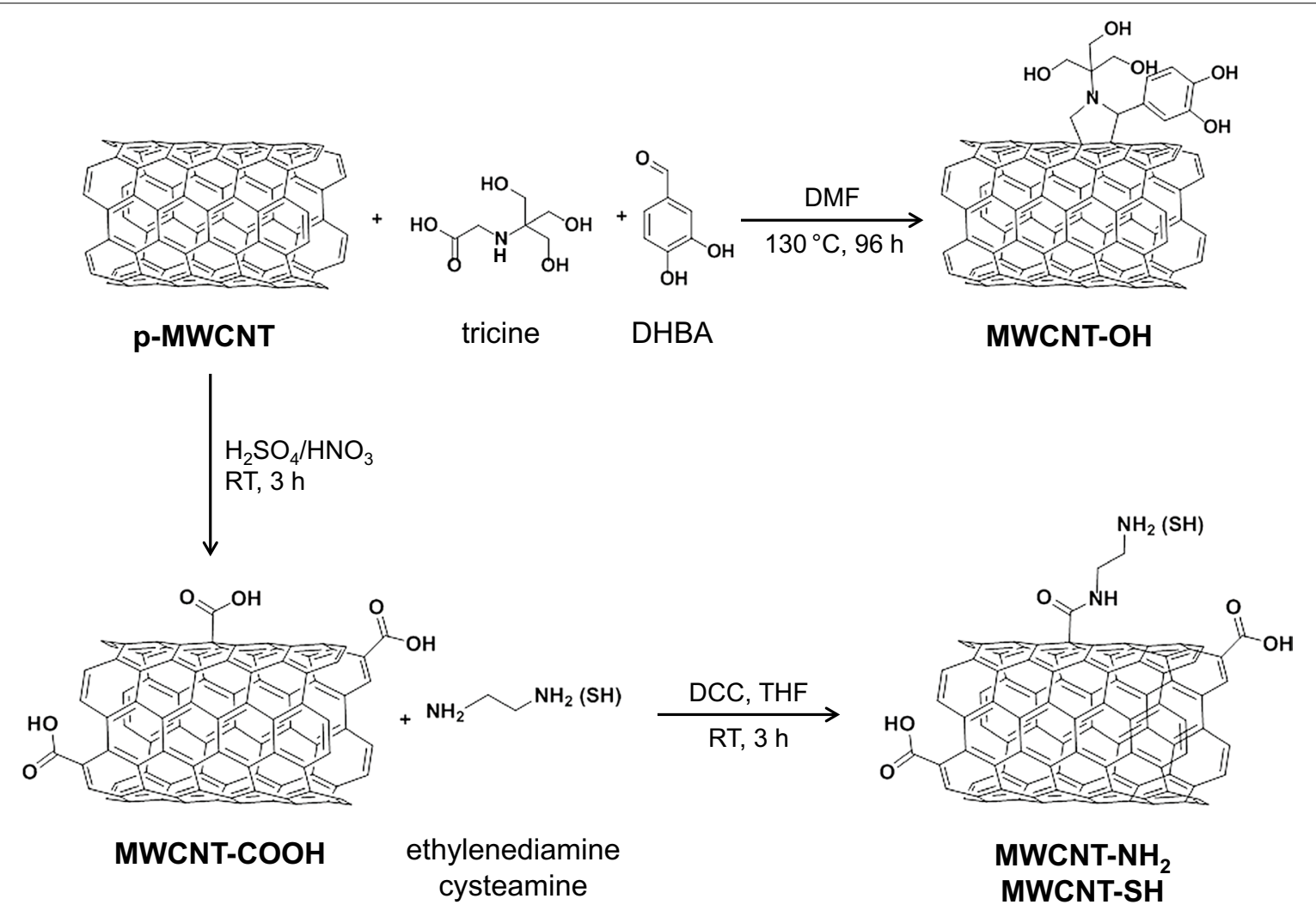

Fig. 1 Scheme for the preparation of functionalized MWCNT from pristine MWCNT. DCC: N,N'-dicyclohexylcarbodiimide; DHBA: 3,4-dihydroxybenzaldehyde; DMF: N,N-dimethylformamide; RT: room temperature; THF: tetrahydrofuran 
infrared spectroscopy (FT-IR) and Raman spectroscopy as described previously $[11,15]$. XPS experiments were carried out in an ultrahigh vacuum system equipped with the hemispherical electron analyzer PHOIBOS 100 (SPECS, Berlin, Germany) operating at constant pass energy $(15 \mathrm{eV})$. The photoelectrons were excited with non-monochromatic $\mathrm{Mg} \mathrm{K \alpha}(1253.6 \mathrm{eV})$ radiation. The $\mathrm{X}$-ray source was run at a power of $300 \mathrm{~W}$. The powder materials were fixed in special sample holders with molds of $4 \mathrm{~mm}$ diameter. The analysis region was approximately $1 \mathrm{~mm}$ in diameter and the resolution was $0.2 \mathrm{eV}$. TGA was carried out in a SDT Q600 (TA Instruments, Eschborn, Germany) with a heating rate of $10 \mathrm{~K} / \mathrm{min}$ and a synthetic air flow of $100 \mathrm{ml} / \mathrm{min}$. FT-IR spectra were recorded at room temperature in transmission mode with an IFS 113v spectrometer (Bruker, Karlsruhe, Germany) with a resolution of $0.5 \mathrm{~cm}^{-1}$. The Raman spectroscopy measurements were performed using a Raman-Fouriertransform-spectrometer DXR SmartRaman (Thermo Fisher Scientific) at a wavelength of $532 \mathrm{~nm}$ and a laser power of $8 \mathrm{~mW}$. The resolution was $1 \mathrm{~cm}^{-1}$.

Stock dispersions of the MWCNT $(1 \mathrm{mg} / \mathrm{ml})$ in phosphate buffered saline (PBS; pH 7.4) were prepared by sonication for $30 \mathrm{~min}$ in an ultrasonic bath. To compare the dispersion stability of the pristine and functionalized MWCNT, dispersions with a MWCNT concentration of $1 \mathrm{mg} / \mathrm{ml}$ were stored at room temperature for $24 \mathrm{~h}$ or three months. MWCNT dilutions for the cellular assays were prepared from the stock dispersions using cell culture medium.

\section{Cell culture, MWCNT treatment and cell viability assay}

The human BCa cell line EJ28 (University of Frankfurt, Frankfurt, Germany) was cultured in Dulbecco's modified eagle's medium (DMEM; 4.5 g/l glucose) with $10 \%$ fetal calf serum, $1 \%$ gentamicin and $1 \%$ non-essential amino acids (all from GE Healthcare, Munich, Germany) in a humidified atmosphere containing $5 \% \mathrm{CO}_{2}$ at $37^{\circ} \mathrm{C}$. After seeding 300 cells per well in 96well plates and adherence for $72 \mathrm{~h}$, cells were treated with $0.1 \mathrm{mg} / \mathrm{ml} \mathrm{MWCNT} \mathrm{dis-}$ persions in DMEM. $24 \mathrm{~h}$ after treatment the medium was changed. Cell viability was examined in quadruplicates 48, 72 and $96 \mathrm{~h}$ after MWCNT treatment start using the cell proliferation reagent WST-1 (Roche, Mannheim, Germany) according to the manufacturer's protocol.

\section{Transmission electron microscopy of MWCNT uptake into cells}

The cellular uptake of MWCNT was investigated by transmission electron microscopy (TEM) studies. 100,000 EJ28 cells were seeded in $25 \mathrm{~cm}^{2}$-flasks. After $72 \mathrm{~h}$ adherent cells were treated with $0.1 \mathrm{mg} / \mathrm{ml}$ MWCNT. Cells without MWCNT treatment served as control. After $24 \mathrm{~h}$ incubation cells were harvested by trypsin/EDTA treatment. TEM samples were prepared by the Institute of Pathology (TU Dresden, Dresden, Germany) as described previously and examined with an EM900 transmission electron microscope (Zeiss, Jena, Germany) [11]. Then, the localization of the MWCNT inside the cells was determined and the amount of cells showing a cellular uptake was estimated.

\section{Mucoadhesion studies}

Mucoadhesive properties of the different functionalized MWCNT were evaluated as described previously [15]. Briefly, explanted mouse bladders (animal facility, Medical Faculty, TU Dresden, Dresden, Germany) were incubated with the various MWCNT types $(0.2 \mathrm{mg} / \mathrm{ml})$ for $1 \mathrm{~h}$ at room temperature using Franz diffusion cells (GauerGlas, Püttlingen, Germany). Subsequently, tissue sections were prepared from formalin-fixed paraffinembedded tissues, stained with hematoxylin-eosin (HE) and evaluated by light microscopy. Percentage of urothelial area covered by MWCNT was considered in relation to total urothelial area by using the software ImageJ (Version 1.4.3.67, Broken Symmetry Software).

\section{Binding of CS-ODN to MWCNT and AS-ODN hybridization}

CS-ODN, AS-ODN and non-complementary nonsense ODN (NS-ODN) as well as amino-group modified CSODN $\left(\mathrm{NH}_{2}-\mathrm{CS}-\mathrm{ODN}\right)$ and maleimide-functionalized CS-ODN (Mal-CS-ODN) were purchased from biomers. net (Ulm, Germany); the respective sequences are listed in Table 1. The selected AS-ODN were targeted at the angiogenic growth factor VEGF [19] and CS-ODN represent the appropriate complementary sequence to the ASODN. The sequence of the NS-ODN was designed in that way that there is no binding to the CS-ODN, which was verified by using the software mfold 2.3 (http://unafold. rna.albany.edu/?q=mfold).

In order to covalently bind CS-ODN to the modified MWCNT, specific activation procedures which are frequently used for the respective modifications of the MWCNT had to be conducted (Table 1). In the following procedures, the concentration of sodium chloride and the ionic strength of the buffer solutions were kept constant in order to have the same ionic conditions in all buffer systems. Furthermore, $1 \mathrm{mg}$ MWCNT was firstly dispersed in $1 \mathrm{ml} \mathrm{PBS} \mathrm{(pH} \mathrm{7.4)} \mathrm{for} 30 \mathrm{~min}$ in an ultrasonic bath and then the respective amount of MWCNT was used for the binding of CS-ODN.

\section{Adsorption of CS-ODN to pristine and modified MWCNT}

$0.5 \mathrm{nmol} \mathrm{CS}-\mathrm{ODN}$ were mixed with $50 \mu \mathrm{g}$ MWCNT in $0.5 \mathrm{ml} \mathrm{PBS}$ and then shaken at room temperature overnight. Afterwards, the excess of CS-ODN was removed 
Table 1 Sequences and intended use of synthetic oligodeoxynucleotides

\begin{tabular}{|c|c|c|}
\hline Type & Sequence & Intended use and remarks \\
\hline CS-ODN & 5'-ACG CTG CCG CCA CCA CAC CA-3' & Adsorbed to pristine and modified MWCNT \\
\hline $\mathrm{NH}_{2}-\mathrm{CS}-\mathrm{ODN}$ & $5^{\prime}-\mathrm{NH}_{2}-\mathrm{C}_{6}-\mathrm{ACG}$ CTG CCG CCA CCA CAC CA-3' & $\begin{array}{l}\text { Covalently bound to EDC/NHS-activated MWCNT-COOH; following activation with DSS } \\
\text { covalently bound to MWCNT-NH }\end{array}$ \\
\hline Mal-CS-ODN & 5'-Mal-ACG CTG CCG CCA CCA CAC CA-3' & Covalently bound to MWCNT-SH \\
\hline AS-ODN & 5'-TGG TGT GGT GGC GGC AGC GT-3' & $\begin{array}{l}\text { Therapeutic AS-ODN against the angiogenic growth factor VEGF, complementary to } \\
\text { CS-ODN }\end{array}$ \\
\hline NS-ODN & 5'-CCA AAC CCG TCA ATC AAG TC-3' & Control, non-complementary to CS-ODN \\
\hline
\end{tabular}

$A S-O D N$ antisense oligodeoxynucleotides, $C S-O D N$ carrier strand oligodeoxynucleotides, $M a l$ maleimide, $M a l-C S-O D N$ maleimide-functionalized CS-ODN, $\mathrm{NH}_{2}$-CS-ODN amino-group modified CS-ODN, NS-ODN nonsense oligodeoxynucleotides

by centrifugation over a centrifugal filter (with modified nylon, pore size $0.2 \mu \mathrm{m}$; VWR International $\mathrm{GmbH}$ ) for $1 \mathrm{~min}$ at $2300 \mathrm{rcf}$ followed by two washing steps with $0.5 \mathrm{ml}$ PBS.

\section{EDC/NHS-activation of MWCNT-COOH and coupling with $\mathrm{NH}_{2}-\mathrm{CS}-\mathrm{ODN}$}

$50 \mu \mathrm{g}$ MWCNT-COOH were activated with $100 \mathrm{mM}$ EDC and $100 \mathrm{mM}$ NHS in $0.5 \mathrm{ml}$ MES (pH 6.0, $100 \mathrm{mM}$ ) by shaking the mixture for $1 \mathrm{~h}$ at room temperature. The buffer was removed by separation of the MWCNT$\mathrm{COOH}$ via centrifugation over a centrifugal filter for $1 \mathrm{~min}$ at $2300 \mathrm{rcf}$. Afterwards, the activated MWCNT$\mathrm{COOH}$ were mixed with $0.5 \mathrm{nmol} \mathrm{NH}_{2}$-CS-ODN in $0.5 \mathrm{ml}$ potassium phosphate buffer $(\mathrm{pH} 8.0)$ and shaken at room temperature overnight followed by the removal of the excess CS-ODN.

\section{Coupling of DSS-activated $\mathrm{NH}_{2}$-CS-ODN to MWCNT-NH}

$25 \mu \mathrm{l}$ of a $1 \mathrm{mM} \mathrm{NH} \mathrm{N}_{2}$-CS-ODN solution in water was mixed with $7.5 \mu \mathrm{l} \mathrm{NaHCO}_{3}$-buffer $(\mathrm{pH} \mathrm{8.6,1} \mathrm{M)} \mathrm{and} 25 \mu \mathrm{l}$ DSS $(10 \mathrm{mg} / \mathrm{ml}$ in DMSO). Excess DSS was separated using an illustra ${ }^{\mathrm{TM}} \mathrm{NAP}^{\mathrm{TM}}-10$ sephadex $^{\mathrm{TM}}$ G-25 column (GE Healthcare, Munich, Germany) and activated ODN were concentrated by Amicon ${ }^{\circledR}$ Ultra centrifugal filters (3000 MWCO; Merck, Darmstadt, Germany). $0.5 \mathrm{nmol}$ of the activated $\mathrm{NH}_{2}$-CS-ODN were mixed with $50 \mu \mathrm{g}$ MWCNT- $\mathrm{NH}_{2}$ in $0.5 \mathrm{ml}$ PBS and shaken at room temperature overnight followed by the removal of the excess CS-ODN.

\section{Coupling of Mal-CS-ODN to MWCNT-SH}

$0.5 \mathrm{nmol}$ Mal-CS-ODN were mixed with $50 \mu \mathrm{g}$ MWCNT$\mathrm{SH}$ in $0.5 \mathrm{ml} \mathrm{PBS}$ and shaken at room temperature overnight followed by the removal of the excess CS-ODN.

\section{AS-ODN hybridization}

AS-ODN or NS-ODN $(0.1 \mathrm{nmol}$ in $200 \mu \mathrm{l} \mathrm{PBS})$ were added onto the centrifugal filters containing $50 \mu \mathrm{g}$
MWCNT and allowed to hybridize for $30 \mathrm{~min}$. The excess of AS-ODN or NS-ODN from the ODN-MWCNT-mixtures was removed by centrifugation over a centrifugal filter for $1 \mathrm{~min}$ at $2300 \mathrm{rcf}$ followed by two washing steps with $0.5 \mathrm{ml}$ PBS.

The aforementioned procedures resulted in the following maximum concentrations of ODN per mg CNT: $10 \mathrm{nmol} / \mathrm{mg}_{\mathrm{CNT}}$ for CS-ODN and $2 \mathrm{nmol} / \mathrm{mg}_{\mathrm{CNT}}$ for ASODN and NS-ODN.

\section{Fluorescence measurements for binding and release studies}

For binding and release studies with the subsequent fluorescence measurements the respective CS-ODN were labeled at the $3^{\prime}$-end, whereas AS-ODN and NS-ODN were labeled at the $5^{\prime}$-end with 6-carboxyfluorescein (6-FAM) for release in PBS or Dy-557 for release in $\mathrm{NaCl}$ and urine. Following binding of the CS-ODN to the various MWCNT the supernatant and the two washing solutions were used for fluorescent measurements. For the release experiments at experimental conditions, $0.5 \mathrm{ml}$ PBS was given to the various MWCNT with attached ODN on the centrifugal filter. The release was carried out at $80{ }^{\circ} \mathrm{C}$ for $10 \mathrm{~min}$ (1. release) and for another $10 \mathrm{~min}$ (2. release). The release at physiological conditions was carried out in $0.9 \% \mathrm{NaCl}$ solution and pure urine as well as mixtures thereof at $37^{\circ} \mathrm{C}$ for $1 \mathrm{~h}$ (1. release) and for $24 \mathrm{~h}$ (2. release). Afterwards, the solutions were centrifuged through the centrifugal filter again to remove the released ODN. The fluorescent measurements of the supernatant, the washing solutions and the release solutions were performed in a precision cuvette made from quartz glass Suprasil ${ }^{\circledR}$ (Hellma GmbH \& Co. KG, Müllheim, Germany) with the F-4500 FL spectrophotometer from Hitachi (Tokio, Japan) with time scan mode for $60 \mathrm{~s}$. The excitation and emission wavelengths for 6-FAM were $\lambda=494$ and $\lambda=515 \mathrm{~nm}$, respectively. For Dy-557 the excitation wavelength was $\lambda=555 \mathrm{~nm}$ and the emission wavelength was $\lambda=576 \mathrm{~nm}$. 


\section{Statistical analyses}

All experiments were reproduced independently at least twice. Data are presented as mean \pm standard deviation, if not otherwise indicated. Outliers were identified by using the Dixon test and were not considered for averaging.

\section{Results}

\section{Characterization of pristine and functionalized MWCNT}

XPS spectra of all samples were measured and the elemental distribution was calculated (Table 2). p-MWCNT did not contain any nitrogen and sulfur. Due to the washing procedure of the sample with nitric acid to remove catalyst particles and amorphous carbon, the p-MWCNT were slightly oxidized resulting in an oxygen content of $1.8 \%$. Compared to p-MWCNT, MWCNT-OH showed an increased content of oxygen (7.3\%) and nitrogen (3.2\%) based on the additional 1,3-dipolar cycloaddition. The sonication in nitric and sulfuric acid increased the oxygen content up to $12.4 \%$ for MWCNT-COOH and incorporated also some nitrogen into the sample $(0.4 \%)$. This acid treatment formed different oxygen-containing functional groups on the surface of the MWCNT-COOH such as hydroxyl and aldehyde groups, but mainly carboxyl groups. The amidation of MWCNT-COOH with ethylenediamine resulted in $\mathrm{MWCNT}-\mathrm{NH}_{2}$ with an increased nitrogen content (4.1\%) combined with a decreased oxygen content (8.5\%), because $\mathrm{OH}$-groups were exchanged for $\mathrm{NH}-\mathrm{CH}_{2}-\mathrm{CH}_{2}-\mathrm{NH}_{2}$ substituents. MWCNT-SH behaved similar to MWCNT-NH $\mathrm{N}_{2}$. The sulfur content of $1.3 \%$ indicated a successful reaction.

The highest overall functionalization degrees were detected for MWCNT-OH $\left(4.4 \mathrm{nmol} / \mathrm{mg}_{\mathrm{CNT}}\right)$ and MWCNT-COOH $\left(4.9 \mathrm{nmol} / \mathrm{mg}_{\mathrm{CNT}}\right) \quad$ (Table 2). In MWCNT-OH five hydroxyl groups were added simultaneously and thus contributed to the high functionalization degree. The functionalization values for $\mathrm{MWCNT}-\mathrm{NH}_{2}$ $\left(1.5 \mathrm{nmol} / \mathrm{mg}_{\mathrm{CNT}}\right)$ and MWCNT-SH $\left(1.0 \mathrm{nmol} / \mathrm{mg}_{\mathrm{CNT}}\right)$ were lower indicating that not all carboxyl groups had been substituted. Furthermore, cysteamine had only one amino group to react with the activated carboxyl group, whereas ethylenediamine had two. This could contribute to the even lower functionalization degree of MWCNT$\mathrm{SH}$ compared to MWCNT- $\mathrm{NH}_{2}$.

TGA measurements (Additional file 1: Figure S1A) showed that $\mathrm{p}-\mathrm{MWCNT}$ were stable until a temperature of $550{ }^{\circ} \mathrm{C}$ and then started to decompose completely to $\mathrm{CO}_{2}$ within a temperature range of $550-650{ }^{\circ} \mathrm{C}$. In contrast, the thermal stability of MWCNT-COOH, MWCNT- $\mathrm{NH}_{2}$ and MWCNT-SH was given until a temperature of $150{ }^{\circ} \mathrm{C}$ and between 150 and $250{ }^{\circ} \mathrm{C}$ they started to oxidize slowly. MWCNT-OH were stable until $250{ }^{\circ} \mathrm{C}$ and then slowly oxidized in a temperature range of $250-320{ }^{\circ} \mathrm{C}$. This much lower thermal stability of all functionalized MWCNT can be attributed to the more unstable functional groups on their surface. Pristine and functionalized MWCNT started to decompose quickly at $550-650{ }^{\circ} \mathrm{C}$. For MWCNT-NH${ }_{2}$ and MWCNT-SH the weight loss before degradation of the MWCNT backbone was higher than for MWCNT-COOH due to the attached groups on the surface of MWCNT- $\mathrm{NH}_{2}$ and MWCNT-SH, which oxidize at lower temperatures.

The FT-IR spectra (Additional file 1: Figure S1B) of all MWCNT showed bands at 3435, 1634 and $1384 \mathrm{~cm}^{-1}$ corresponding to $\mathrm{O}-\mathrm{H}, \mathrm{C}=\mathrm{O}$ and $\mathrm{C}-\mathrm{O}$ bonds, respectively. In addition, MWCNT- $\mathrm{NH}_{2}$ and MWCNT-SH exhibited another $\mathrm{C}=\mathrm{O}$ stretching vibration (amide group) at $1580 \mathrm{~cm}^{-1}$, which confirmed the successful amidation with ethylenediamine or cysteamine of these samples.

The Raman spectra (Additional file 1: Figure S1C) showed for all samples the two standard peaks at $1350 \mathrm{~cm}^{-1}$ (G-band) and $1591 \mathrm{~cm}^{-1}$ (D-band), which corresponded to graphitic and non-graphitic carbon, respectively. The ratio between the G-band and the D-band did not change during the functionalization processes. Raman spectroscopy was not sensitive enough to visualize the differences in the samples.

In order to examine the dispersibility of the MWCNT and the long-term behavior of their dispersions, MWCNT in PBS were sonicated followed by a monitoring of the dispersions. Homogenous dispersions were only obtained for the functionalized MWCNT (Additional file 1: Figure S2). In contrast, p-MWCNT could

Table 2 Results of XPS measurements of pristine and functionalized MWCNT

\begin{tabular}{|c|c|c|c|c|c|}
\hline Sample & C 1s [\%] & N 1s [\%] & O 1s [\%] & S 2s [\%] & $\begin{array}{l}\text { Functionalization degree } \\
{\left[\mathrm{nmol} / \mathrm{mg}_{\mathrm{CNT}}\right]}\end{array}$ \\
\hline p-MWCNT & 98.2 & 0.0 & 1.8 & 0.0 & - \\
\hline MWCNT-OH & 89.5 & 3.2 & 7.3 & 0.0 & 4.4 \\
\hline MWCNT-COOH & 86.1 & 0.4 & 12.4 & 0.0 & 4.9 \\
\hline MWCNT-NH & 87.4 & 4.1 & 8.5 & 0.0 & 1.5 \\
\hline MWCNT-SH & 89.4 & 2.3 & 7.0 & 1.3 & 1.0 \\
\hline
\end{tabular}


not be dispersed sufficiently in PBS and consequently coarse agglomerates were observed. $24 \mathrm{~h}$ after sonication, sedimentation of all dispersions was detected with p-MWCNT showing the highest sedimentation rate. The functionalized MWCNT could easily be converted back into dispersion by soft agitation of the sample vessel. After incubation for three months, all samples showed the same sedimentation behavior as observed at the $24 \mathrm{~h}$ time point.

\section{Impact of pristine and functionalized MWCNT on the cell viability of EJ28 BCa cells}

Next, the impact of $0.1 \mathrm{mg} / \mathrm{ml}$ pristine and functionalized MWCNT on cellular viability was tested in EJ28 BCa cells. $48 \mathrm{~h}$ after treatment start, all MWCNT modifications caused a considerable inhibition of cellular viability (Fig. 2), whereupon MWCNT-COOH and p-MWCNT caused the strongest reduction of the relative cell viability down to about $40 \%$. In contrast, the relative cell viability following treatment with MWCNT-OH, MWCNT$\mathrm{NH}_{2}$ and MWCNT-SH was approximately $60 \%$ after $48 \mathrm{~h}$. However, the relative cell viability increased over the investigated time period resulting in the lowest inhibition for all MWCNT modifications $96 \mathrm{~h}$ after treatment start. At this time point, the relative cell viability was $60 \%$ for MWCNT-COOH, $75 \%$ for p-MWCNT and between 82 and $94 \%$ for MWCNT-OH, MWCNT-NH and MWCNT-SH. The detrimental impact of the various MWCNT on the cell viability was as follows: MWCNT$\mathrm{COOH}>$ p-MWCNT $>$ MWCTNs-OH/MWCNT-NH ${ }_{2} /$ MWCNT-SH.

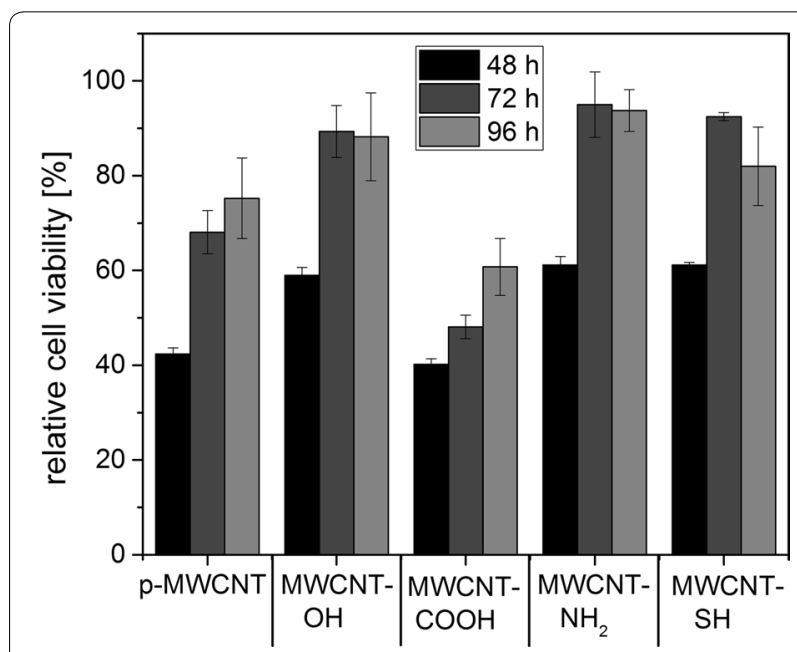

Fig. 2 Time-dependent influence of pristine and functionalized MWCNT on the relative cell viability of EJ28 cells. Cells were treated for $24 \mathrm{~h}$ with $0.1 \mathrm{mg} / \mathrm{ml}$ MWCNT and then cellular viability was measured 48,72 and $96 \mathrm{~h}$ after treatment start by using the WST-1 assay. Untreated cells served as control (100\%)
Cellular uptake of pristine and functionalized MWCNT Additionally, the cellular uptake of MWCNT was investigated with TEM analysis (Fig. 3). The vacuoles of untreated cells were significantly smaller than the vacuoles of treated cells. The MWCNT taken up by the cells could be mostly found as agglomerates in the vacuoles. No MWCNT were located in the cell nuclei. After treatment with p-MWCNT 5-10\% of cells showed an uptake, whereas for MWCNT-COOH and MWCNT-NH $30-35 \%$ of cells exhibited a MWCNT uptake. MWCNTSH showed the lowest uptake with $5 \%$ of cells having MWCNT-SH inside their vacuoles. After treatment with MWCNT-OH, $40 \%$ of cells showed an uptake, whereupon $90 \%$ of the incorporated MWCNT-OH could be found in vacuoles and $10 \%$ were included directly in the cytoplasm of cells. MWCNT-OH in the cytoplasm were individualized and not agglomerated like in the vacuoles (Additional file 1: Figure S3).

\section{Mucoadhesive potential of pristine and functionalized MWCNT}

Next, ex vivo mucoadhesion experiments of the pristine and modified MWCNT were performed on explanted mouse bladders. All MWCNT types displayed only an adhesion to the urothelium and did not penetrate into deeper tissue layers. Furthermore, the surface of the mouse bladders showed no visible signs of damage following incubation with MWCNT. The mean percentages of MWCNT-covered surface areas along the urothelium were estimated to evaluate the mucoadhesive properties of the different modified MWCNT types (Fig. 4) and ranged from $2.3 \%$ for MWCNT-OH to $5.9 \%$ for MWCNT-COOH. The unmodified p-MWCNT showed a slightly higher mean percentage $(6.7 \%)$ of covered surface area of the urothelium than the modified MWCNT.

\section{Binding of CS-ODN to MWCNT}

In the present study, two different strategies were employed in order to attach CS-ODN to the MWCNT: via non-covalent adsorption and covalent binding. Because a fluorescence quenching occurred when measuring fluorescent-labeled CS-ODN directly on the surface of MWCNT, the amount of CS-ODN coupled to MWCNT could only be measured indirectly. By measuring the amount of CS-ODN in the supernatant of the binding reaction and in the washing solutions an estimation of coupled CS-ODN to the surface of MWCNT was possible. A high concentration of CS-ODN in these solutions would indicate a poor attachment to the MWCNT. Furthermore, a release study was performed at $80{ }^{\circ} \mathrm{C}$, because it has been shown that non-covalent interactions are not stable at higher temperatures resulting in a release of the CS-ODN [20]. 

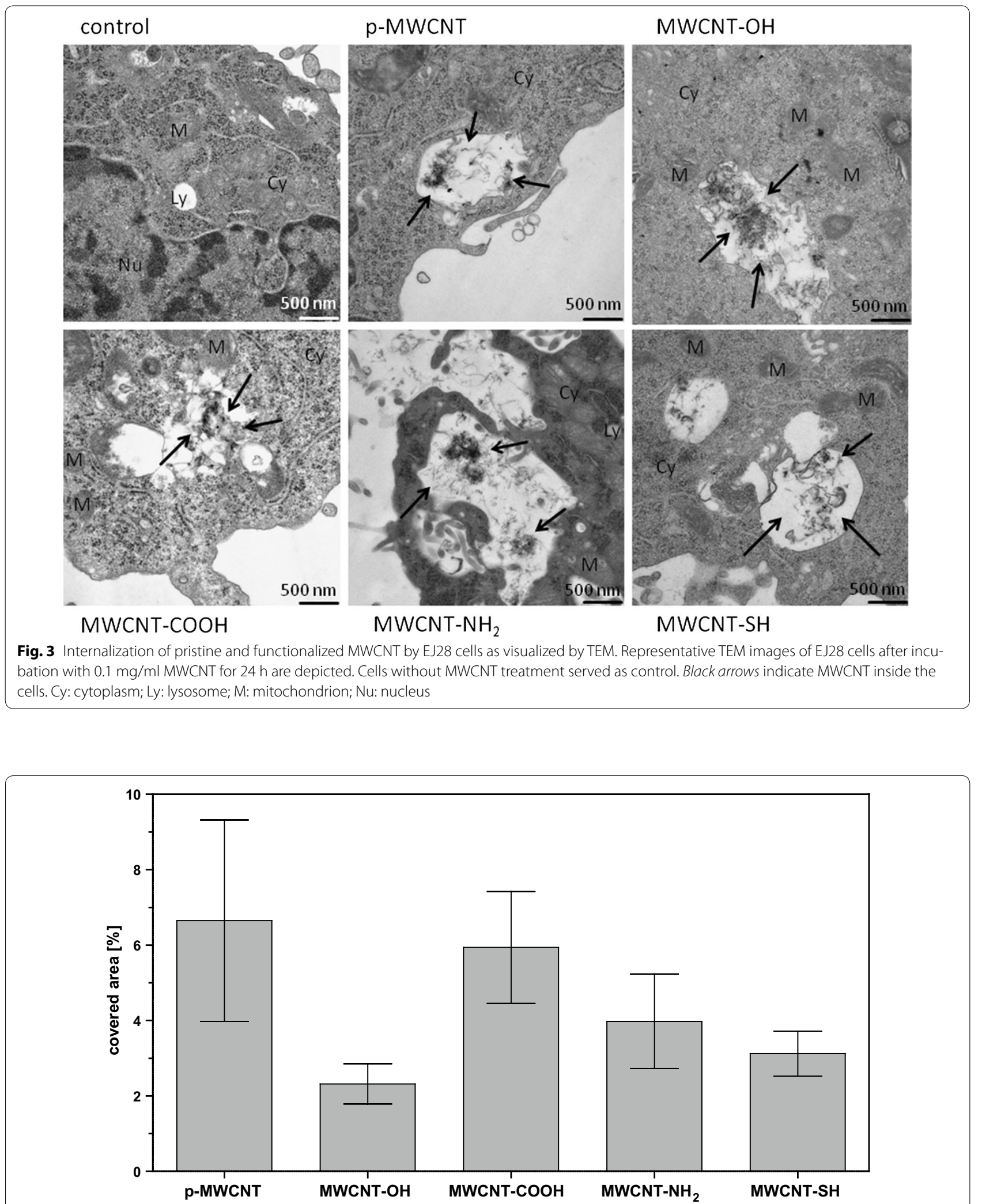

Fig. 4 Mean percentage of urothelial area covered by pristine or functionalized MWCNT. Explanted mouse bladders were incubated with the various MWCNT types $(0.2 \mathrm{mg} / \mathrm{ml})$ for $1 \mathrm{~h}$ at room temperature using Franz diffusion cells. Subsequently, the coverage of urothelium by MWCNT was evaluated on HE-stained tissue sections by light microscopy. Results are depicted as mean \pm standard error 
First, the non-covalent adsorption of CS-ODN to pristine and modified MWCNT was investigated (Fig. 5a). The lowest amount of CS-ODN in the supernatant was achieved for $\mathrm{p}$-MWCNT with $0.30 \mathrm{nmol} / \mathrm{mg}_{\mathrm{CNT}}$. Additionally, there were no CS-ODN in the washing and releasing solutions. Altogether, this indicates a good adsorption capacity and stability for CS-ODN to p-MWCNT. The highest amount of CS-ODN in the supernatant was measured for MWCNT-OH with $7.60 \mathrm{nmol} / \mathrm{mg}_{\mathrm{CNT}}$ followed by $7.20 \mathrm{nmol} / \mathrm{mg}_{\mathrm{CNT}}$ in the supernatant after CS-ODN-adsorption to MWCNT$\mathrm{SH}$. Additionally, there was a rather high release at $80^{\circ} \mathrm{C}$ for these MWCNT modifications. Therefore, the major part of the initially added CS-ODN $\left(10 \mathrm{nmol} / \mathrm{mg}_{\mathrm{CNT}}\right)$ was not coupled to the surface of MWCNT-OH and MWCNT-SH. For MWCNT-NH ${ }_{2}$ and MWCNT-COOH the CS-ODN concentration in the supernatant was 2.30 and $1.70 \mathrm{nmol} / \mathrm{mg}_{\mathrm{CNT}}$, respectively. The amount of CS-ODN in the washing and release solutions was also lower compared to MWCNT-OH and MWCNT-SH. The adsorption capacity and stability of CS-ODN to MWCNT reflected by a decreasing amount CS-ODN in the supernatant, washing and releasing solutions were as follows: p-MWCNT > MWCNT-COOH > MWCNT$\mathrm{NH}_{2}>$ MWCNT-SH $>$ MWCNT-OH.

Next, functionalized MWCNT were used for the covalent coupling of fluorescent-labeled CS-ODN. First, the carboxyl-groups of MWCNT-COOH were activated by EDC/NHS-treatment, so that they then could react with the amino-groups of amino-group-modified CSODN $\left(\mathrm{NH}_{2}\right.$-CS-ODN). The amount of $\mathrm{NH}_{2}$-CS-ODN in the supernatant after EDC/NHS-activation and in the first release solution was about 2.60 and $0.30 \mathrm{nmol} /$ $\mathrm{mg}_{\mathrm{CNT}}$, respectively, indicating a moderate to good binding capacity and stability (Fig. 5b). Surprisingly, the amount of $\mathrm{NH}_{2}$-CS-ODN in the supernatant and after the release was nearly zero for $\mathrm{NH}_{2}$-CS-ODN coupled to MWCNT-COOH without EDC/NHS-activation reflecting a better binding capacity and stability than with EDC/ NHS-activation.

$\mathrm{NH}_{2}$-CS-ODN were activated by DSS and used for a covalent binding to the amino-groups of MWCNT$\mathrm{NH}_{2}$. In comparison to the non-covalent binding of $\mathrm{NH}_{2}$-CS-ODN without DSS-activation to MWCNT$\mathrm{NH}_{2}$, the amount of $\mathrm{NH}_{2}-\mathrm{CS}-\mathrm{ODN}$ in the supernatant and after release for DSS-activated $\mathrm{NH}_{2}$-CS-ODN to MWCNT-NH $\mathrm{N}_{2}$ was much lower (Fig. 5b): 0.07 vs $1.60 \mathrm{nmol} / \mathrm{mg}_{\mathrm{CNT}}$ and 0.07 vs $0.30 \mathrm{nmol} / \mathrm{mg}_{\mathrm{CNT}}$, respectively. This indicates a specific binding reaction and strength for the DSS-activated $\mathrm{NH}_{2}$-CS-ODN to MWCNT- $\mathrm{NH}_{2}$.

For maleimide-functionalized CS-ODN (Mal-CSODN), which react with thiol groups of MWCNT-SH, the situation was similar (Fig. 5b). The direct comparison
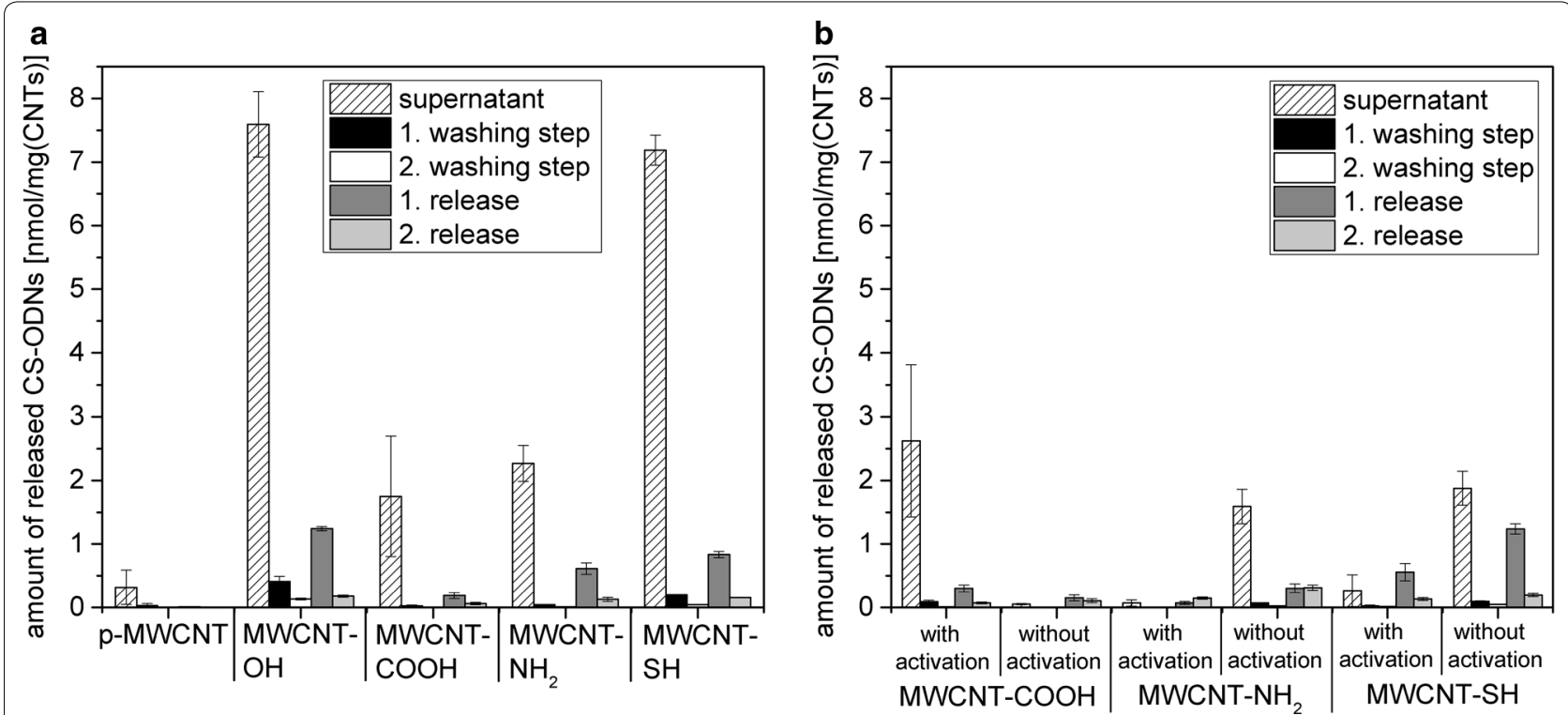

Fig. 5 Release of CS-ODN attached to pristine or functionalized MWCNT. Depicted is the amount of released CS-ODN following a adsorption or $\mathbf{b}$ covalent binding with and without prior activation to pristine or modified MWCNT. The initial concentration of the 6-FAM-labeled CS-ODN was $10 \mathrm{nmol} / \mathrm{mg}_{\mathrm{CNT}}$ and the released amount was determined by fluorescence measurements in the supernatant of the binding reaction, in the washing solution (twice with PBS) and in the release solution (in PBS at $80^{\circ} \mathrm{C}$ for $2 \times 10 \mathrm{~min}$ ). The specific activation procedures prior to the covalent binding were as follows: $\mathrm{NH}_{2}-\mathrm{CS}-\mathrm{ODN}$ coupled to MWCNT-COOH activated with EDC/NHS, DSS-activated $\mathrm{NH}_{2}-\mathrm{CS}-\mathrm{ODN}$ coupled to MWCNT-NH${ }_{2}$, maleimide-activated CS-ODN coupled to MWCNT-SH. Control experiments were performed without specific activation 
of Mal-CS-ODN coupled to MWCNT-SH and CSODN without maleimide-functionalization adsorbed to MWCNT-SH showed a CS-ODN concentration of 0.30 and $1.90 \mathrm{nmol} / \mathrm{mg}_{\mathrm{CNT}}$, respectively, in the supernatants. Also, the CS-ODN amount in the releasing solutions was lower for Mal-CS-ODN coupled to MWCNT-SH compared to CS-ODN without maleimide-functionalization. This demonstrates that Mal-CS-ODN could be covalently and specifically coupled to MWCNT-SH resulting in a good binding stability.

The binding capacity and stability of CS-ODN to the modified MWCNT after specific activation were as follows: MWCNT-NH ${ }_{2}>$ MWCNT-SH > MWCNT-COOH.

\section{Hybridization of AS-ODN to CS-ODN-MWCNT and release at experimental conditions}

After adsorption or covalent coupling of CS-ODN to MWCNT, the complementary AS-ODN could hybridize to them. Non-complementary NS-ODN served as control to show the specificity of the AS-ODN-hybridization to the CS-ODN. Afterwards, the release of AS-ODN and NS-ODN was performed at $80{ }^{\circ} \mathrm{C}$, which is above the melting temperature of AS-ODN and NS-ODN ensuring a high release rate. Regardless of the attachment method of the CS-ODN to the MWCNT, most of the AS-ODN were already released after $10 \mathrm{~min}$ at $80^{\circ} \mathrm{C}$ in PBS (1. release) and only small amounts of AS-ODN were released after additional $10 \mathrm{~min}$ (2. release; Fig. 6).
The first release of AS-ODN from CS-ODN which were adsorbed to MWCNT was highest for MWCNT$\mathrm{NH}_{2} \quad\left(0.20 \mathrm{nmol} / \mathrm{mg}_{\mathrm{CNT}}\right)$ followed by MWCNT-OH $\left(0.16 \mathrm{nmol} / \mathrm{mg}_{\mathrm{CNT}}\right)$, MWCNT-SH $\left(0.11 \mathrm{nmol} / \mathrm{mg}_{\mathrm{CNT}}\right)$ and MWCNT-COOH $\left(0.09 \mathrm{nmol} / \mathrm{mg}_{\mathrm{CNT}}\right)$ (Fig. 6a). The lowest release of AS-ODN with $0.05 \mathrm{nmol} / \mathrm{mg}_{\mathrm{CNT}}$ was achieved for p-MWCNT (Fig. 6a), although they had the highest amount of adsorbed CS-ODN as aforementioned. The release of AS-ODN from CS-ODN covalently bound to MWCNT-COOH $\left(0.26 \mathrm{nmol} / \mathrm{mg}_{\mathrm{CNT}}\right)$, MWCNT-NH $\left(0.25 \mathrm{nmol} / \mathrm{mg}_{\mathrm{CNT}}\right)$ or MWCNT-SH $\left(0.34 \mathrm{nmol} / \mathrm{mg}_{\mathrm{CNT}}\right)$ were similar amongst these MWCNT with MWCNT$\mathrm{SH}$ showing a slightly higher release rate (Fig. 6b). For all samples the release of NS-ODN was clearly lower than for AS-ODN indicating the specific hybridization of ASODN to the CS-ODN at the MWCNT surface (Fig. 6).

While comparing the release of NS-ODN, which can only adsorb to the MWCNT, with the amount of released AS-ODN it is possible to estimate the ratio of unspecific adsorption for AS-ODN. The difference between the release of NS-ODN and AS-ODN, which corresponds to the hybridization rate of AS-ODN, was highest for MWCNT-OH. In detail, eight times more AS-ODN than NS-ODN were released from MWCNT-OH, which corresponds to a adsorption rate of AS-ODN to MWCNT$\mathrm{OH}$ of $12.5 \%$ compared to NS-ODN with an estimated adsorption rate of $100 \%$. The estimated adsorption rate of AS-ODN was $20 \%$ for MWCNT- $\mathrm{NH}_{2}$ and $33 \%$ for
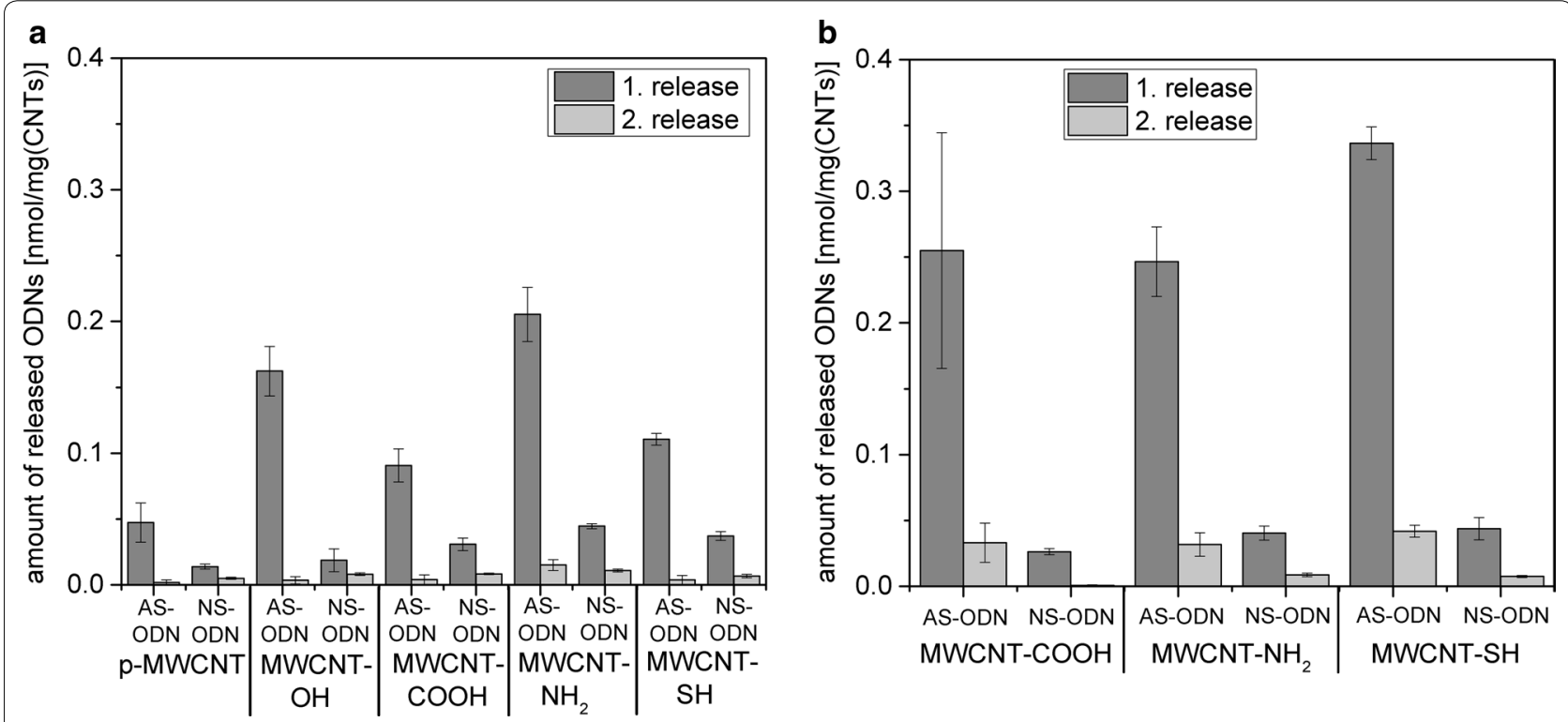

Fig. 6 Release of AS-ODN or NS-ODN following hybridization to CS-ODN attached to pristine or functionalized MWCNT. Depicted is the amount of released AS-ODN or NS-ODN following hybridization to $\mathbf{a}$ adsorbed or $\mathbf{b}$ covalently bound CS-ODN to pristine or modified MWCNT. The initial concentration of the 6-FAM-labeled AS-ODN and NS-ODN was $2 \mathrm{nmol} / \mathrm{mg}_{\mathrm{CNT}}$ and the released amount was determined by fluorescence measurements in the release solution (in PBS at $80^{\circ} \mathrm{C}$ for $2 \times 10 \mathrm{~min}$ ). The specific activation procedures prior to the covalent binding were performed analog to Fig. 2. Non-complementary NS-ODN served as control 
p-MWCNT, MWCNT-COOH and MWCNT-SH. Consequently, CS-ODN adsorbed to MWCNT-OH and MWCNT- $\mathrm{NH}_{2}$ had the highest hybridization rate of AS-ODN.

\section{Release of AS-ODN at physiological conditions in urine}

For prospective medical applications MWCNT carrying therapeutic AS-ODN should be instilled into the urinary bladder in a physiological $\mathrm{NaCl}$ solution (0.9\%). Therefore and exemplarily, the release of AS-ODN after hybridization to CS-ODN adsorbed to MWCNT-OH was investigated at $37{ }^{\circ} \mathrm{C}$ using $0.9 \% \mathrm{NaCl}$ solution and pure urine as well as mixtures thereof (Fig. 7). The release of AS-ODN was lowest in the $0.9 \% \mathrm{NaCl}$ solution and increased with an increasing portion of urine in the mixture. Accordingly, the release of AS-ODN was the highest in pure urine: $0.19 \mathrm{nmol} / \mathrm{mg}_{\mathrm{CNT}}$ after $1 \mathrm{~h}$ and $0.20 \mathrm{nmol} /$ $\mathrm{mg}_{\mathrm{CNT}}$ after $24 \mathrm{~h}$.

\section{Discussion}

CNT may represent a viable option as gene therapy vectors, because they can be chemically tailored at the surface in order to improve drug binding, dispersibility, biocompatibility and/or targeting [6]. Furthermore, $\mathrm{CNT}$ are known to penetrate cell membranes and thus could unload their cargo intracellularly $[6,8]$. Because p-MWCNT are usually difficult to disperse in aqueous solutions, various types of surface functionalization with hydrophilic moieties are employed not only to increase their dispersibility, but also to improve their biocompatibility. In the present study, p-MWCNT were functionalized with hydroxyl groups (MWCNT-OH)

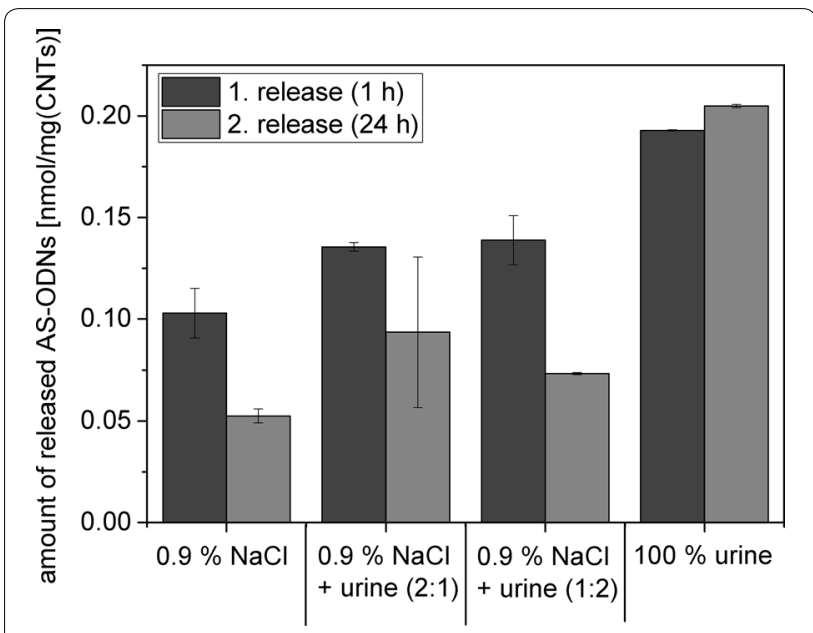

Fig. 7 Release of AS-ODN following hybridization to CS-ODN adsorbed to MWCNT-OH at physiological conditions. The initial concentration of the Dy-557-labeled AS-ODN was $2 \mathrm{nmol} / \mathrm{mg}_{\text {CNT }}$ and the released amount was determined by fluorescence measurements in the release solutions. The release studies were performed at $37^{\circ} \mathrm{C}$ in $0.9 \% \mathrm{NaCl}$ solution, urine and different dilutions thereof via 1,3-dipolar cycloaddition of tricine/DHBA and with carboxylic groups (MWCNT-COOH) by oxidation with nitric and sulfuric acid. The amino groups (MWCNT$\mathrm{NH}_{2}$ ) were introduced by the formation of an amide bond between ethylene diamine and carboxylic groups of MWCNT-COOH, whereas cysteamine was used instead of ethylene diamine for the attachment of thiol groups (MWCNT-SH). Depending on the moiety the degree of functionalization ranged between 1.0 and $4.9 \mathrm{nmol} /$ $\mathrm{mg}_{\mathrm{CNT}}$. By increasing the functionalization degree the MWCNT showed a much lower thermal stability due to the more unstable functional groups on their surface. MWCNT- $\mathrm{NH}_{2}$ and MWCNT-SH started to decompose at lower temperatures in comparison to all other functionalized MWCNT, because the oxidation of these functional groups occurred at lower temperatures. Furthermore, the ratio between the G-band and the D-band did not change during the functionalization processes indicating that no further defects were introduced into the modified MWCNT.

The prerequisite for the biomedical application of MWCNT is the formation of stable dispersions without agglomerates or aggregates. Therefore, an initial assessment of the dispersibility and the long-term dispersion stability of the different MWCNT modifications was performed. The introduction of hydrophilic moieties to the MWCNT surface led to a superior dispersibility and enhanced dispersion stability compared to unmodified p-MWCNT. Notably, the functionalized MWCNT formed good dispersions in PBS without the help of known adjuvants such as serum albumin and polyethylene glycol [21]. In the present study, the MWCNT modifications MWCNT-OH, MWCNT- $\mathrm{NH}_{2}$ and MWCNT-SH exhibited a lower impact on the cellular viability of EJ28 BCa cells than oxidized MWCNT$\mathrm{COOH}$ and unmodified p-MWCNT. Due to their hydrophobic surface, p-MWCNT are poorly dispersible in aqueous solutions and tend to agglomerate and thus induce higher cell-damaging effects than well-dispersed MWCNT as proven by various studies [22, 23]. In accordance with our results, various in vitro and in vivo studies revealed that acid-treated SWCNT and MWCNT with carboxyl groups caused a substantial degree of cytotoxicity and/or inflammatory response [22-25]. These strong toxic effects might be evoked by their high negative surface charge, which could lead to enhanced CNTcell-interactions [24]. In contrast and similar to our findings, MWCNT-OH were demonstrated to be less toxic than p-MWCNT or MWCNT-COOH [23]. Furthermore, Muller et al. have shown that the presence of structural defects at the surface of MWCNT is associated with a diminished biocompatibility due to a higher reactivity of the defective MWCNT [26]. However, in 
the present study this should not be the case, because it has been shown by Raman spectroscopy that no further defects have been introduced by the functionalization process. Moreover, it was shown that EJ28 BCa cells could recover over the investigated time period following incubation with pristine or modified MWCNT. In accordance, we could previously demonstrate that EJ28 $\mathrm{BCa}$ cells treated with different $\mathrm{p}-\mathrm{MWCNT}$ varying in diameter and length could recover over time [15].

Furthermore, a general uptake of all investigated MWCNT into cells was observed. Cellular internalization into various cell types has already been shown for p-MWCNT, MWCNT-OH and MWCNT-COOH in our previous studies or by other groups [11, 16, 22, 23]. Here, the percentage of cells with internalized MWCNT ranged from 5 to $40 \%$ depending on the functional group of the MWCNT, whereupon MWCNT-OH had the highest and MWCNT-SH the lowest rates of internalization. The majority of MWCNT was located as agglomerates inside vacuoles, which were hence enlarged due to the uptake of MWCNT. This indicates that MWCNT were incorporated into the cells as cellular vesicles by energy-dependent endocytosis, which is one possibility for the uptake of CNT $[8,27]$. Another possibility is the passive uptake by nanopenetration leading to the location of the MWCNT directly in the cytoplasm of cells $[8,27]$. Of all investigated MWCNT within the present work, this could only be shown for MWCNT-OH. Ursini et al. also demonstrated that MWCNT-OH were localized freely in the cytoplasm and inside vacuoles, whereas MWCNT-COOH were only found inside vacuoles [23]. Furthermore, pristine and modified MWCNT were able to adhere to the urothelium of explanted mouse bladders. Similar to our previous findings with various $\mathrm{p}-\mathrm{MWCNT}$ [15], all tested MWCNT types did not penetrate into deeper tissue layers and induced no visible signs of damage on the surface of the mouse bladders. However, the amount of the covered area was rather low (2-7\%) and thus it was not possible to clearly identify the superiority of one modification over the other regarding their mucoadhesive potential. In a previous study by our group, different types of p-MWCNT led to similar percentages of covered urothelium from mouse bladders $(5-10 \%)$ [15]. Apart from the present and our previous study, the mucoadhesive potential with regard to bladder treatment has so far only been investigated for nanoparticles other than CNT using in vitro or ex vivo methods [28-35]. CNT could also be coated or functionalized with hydrophilic polymers such as gelatin or chitosan, which could further increase the dispersibility, biocompatibility and mucoadhesion $[3,36]$.

In addition to conventional drugs, MWCNT can also be loaded with therapeutic nucleic acids such as
AS-ODN or siRNA [6-8]. AS-ODN, for instance, can be coupled to MWCNT via complementary carrier strands (CS-ODN), which have been either covalently or noncovalently bound to MWCNT beforehand. In the present study, we could successfully attach CS-ODN by adsorption and covalent binding to the various MWCNT types. In order to evaluate the binding capacity and stability of CS-ODN to MWCNT, the amount of unbound fluorescent-labeled CS-ODN was determined in the supernatant of the binding reaction, the washing and release solutions. This approach was necessary, because the fluorescence quenching effect of MWCNT hindered the direct quantification of bound CS-ODN. Adsorption of CSODN to p-MWCNT, MWCNT-COOH and MWCNT$\mathrm{NH}_{2}$ as well as covalent coupling to MWCNT- $\mathrm{NH}_{2}$ and MWCNT-SH resulted in the best binding capacity and stability as indicated by low concentrations of CS-ODN in the supernatant, washing and releasing solutions.

However, it is difficult to distinguish between covalent and non-covalent binding of CS-ODN to the CNT. The results suggest that the binding of CS-ODN to MWCNT was easier achieved by adsorption, particularly for MWCNT-COOH. Covalent binding and adsorption are competing processes. Through its strong affinity and spontaneity the adsorption process is probably more dominant than the slower covalent reaction. This thesis was also confirmed, because p-MWCNT displayed the highest amount of bound CS-ODN. The presence of functional groups at the surface of MWCNT could possibly hinder the adsorption of CS-ODN to the functionalized MWCNT. Responsible forces for an enhanced non-covalent adsorption of CS-ODN to MWCNT may be London dispersion forces and $\pi-\pi$-interactions between aromatic nucleobases and the aromatic graphene rings of the MWCNT. Also, hydrogen bonds can be formed between nucleobases or the sugar-phosphatebackbone and hydroxyl-groups of MWCNT-COOH and MWCNT-OH or amino-groups of MWCNT-NH $\mathrm{N}_{2}$. Because the aromatic rings of the nucleobases and the MWCNT surface are hydrophobic, there are hydrophobic interactions between both. Furthermore, electrostatic interactions could occur between negatively charged CS-ODN and the positively charged MWCNTSH and MWCNT- $\mathrm{NH}_{2}$ at neutral pH. p-MWCNT and MWCNT-OH are uncharged at neutral $\mathrm{pH}$, whereas MWCNT-COOH are negatively charged, which could cause a repulsion with CS-ODN.

Subsequently, therapeutic AS-ODN could be hybridized to and reversibly released from the CS-ODN coupled via both strategies to the functionalized MWCNT. At experimental conditions $\left(80{ }^{\circ} \mathrm{C}\right.$, buffer), the release of AS-ODN from CS-ODN adsorbed to MWCNT was most effective from MWCNT-OH and MWCNT- $\mathrm{NH}_{2}$ 
followed by MWCNT-COOH and MWCNT-SH. The lowest release of AS-ODN was achieved for p-MWCNT despite the highest amount of adsorbed CS-ODN. The release of AS-ODN from CS-ODN covalently attached to MWCNT-COOH, MWCNT- $\mathrm{NH}_{2}$ or MWCNT-SH were similar and thus did not depend on the type of MWCNT functionalization. For all samples the specific hybridization of AS-ODN to the CS-ODN at the MWCNT surface was indicated by the much lower release rate of NSODN, which can only adsorb to the MWCNT. However, it was not possible to experimentally distinguish between hybridization of AS-ODN to CS-ODN and a potential adsorption of AS-ODN to the MWCNT surface. Therefore, it might be possible that AS-ODN also adsorbed to free positions at the MWCNT surface in addition to hybridization to CS-ODN. By comparing the release of NS-ODN, which can only adsorb to the MWCNT, with the amount of released AS-ODN it was possible to estimate the ratio of unspecific adsorption for AS-ODN. The highest hybridization rate of AS-ODN was observed for CS-ODN adsorbed to MWCNT-OH and MWCNT-NH ${ }_{2}$. This could in turn result in the superior release rate of AS-ODN from these MWCNT modifications, because hybridization is a reversible process and hybridized AS-ODN might be easier released than the additional adsorbed portion.

Moreover, we could exemplarily demonstrate that ASODN could be released following hybridization to CSODN adsorbed to MWCNT-OH at physiological settings (37 ${ }^{\circ} \mathrm{C}$, urine). The release in urine and $\mathrm{NaCl}$ as well as mixtures thereof was carried out to investigate the clinical applicability of the AS-ODN release from MWCNT. $0.9 \% \mathrm{NaCl}$ solution is normally used as clinical instillation solution. The release of AS-ODN was lowest in $0.9 \% \mathrm{NaCl}$, whereas with an increasing amount of urine the release of AS-ODN also increased. It is possible that the stability of the AS-ODN hybridization is higher in the $\mathrm{NaCl}$ solution, because there is a higher concentration of monovalent counterions, which shield the phosphate-phosphate repulsion inside the double helix. When the urea concentration increases, the electrostatic forces between the negatively charged DNA phosphate backbone and sodium ions are decreasing leading to an enhanced release of AS-ODN. Furthermore, there are hydrogen bonds preferentially formed between nucleobases and urea instead of complementary base pairing, which causes a destabilization of the double helix and a release of AS-ODN [37]. In summary, for a clinical application it will be advantageous, when there is no release during instillation with $\mathrm{NaCl}$. This will ensure that the release of AS-ODN first starts inside the bladder, when an increasing amount of urea facilitates the destabilization of the AS-ODN/CS-ODN-bond.
To date, only a few groups have investigated CNT as delivery vectors for AS-ODN or ODN. Jia et al. could efficiently transport AS-ODN against telomerase into cell nuclei by means of polyethylenimine-functionalized MWCNT-COOH, which led to a much higher cellular apoptosis than cell transfection with naked AS-ODN [13]. AS-ODN against c-myc conjugated to MWCNT$\mathrm{NH}_{2}$ modified with polyamidoamine dendrimers could mediate a substantial inhibition of cell growth and c-myc expression [14]. Furthermore, SWCNT-COOH served as efficient vector for the intracellular delivery of decoy ODN against NF- $\kappa B$, which hence could significantly diminish the NF- $k B$-dependent gene expression [12]. In our previous study, AS-ODN against the angiogenic growth factor VEGF could be released after hybridization to CS-ODN adsorbed onto MWCNT-OH at physiological conditions $\left(37^{\circ} \mathrm{C}\right.$, buffer) at slightly basic $\mathrm{pH}$ values. MWCNT-OH could also mediate an uptake of AS-ODN into EJ28 BCa cells, which resulted in a marginal inhibition of cellular viability and VEGF expression [11]. However, other targets with more relevance to BCa such as survivin [38] and hTERT [39] could mediate more pronounced anti-proliferative effects upon inhibition through AS-ODN than VEGF. This should be investigated in future studies.

\section{Conclusions}

We could successfully functionalize p-MWCNT with hydrophilic moieties (MWCNT-OH, - $\mathrm{COOH},-\mathrm{NH}_{2}$, $-\mathrm{SH}$ ), which led to an improved dispersibility and dispersion stability as well as to an enhanced biocompatibility for most of the modifications. All MWCNT were internalized by $\mathrm{BCa}$ cells and could adhere to the urothelium of explanted mouse bladders, although the amount of the covered urothelial area was rather low. AS-ODN could be hybridized to CS-ODN which were either adsorbed or covalently bound to pristine or functionalized MWCNT. However, the reversible release of AS-ODN at experimental conditions $\left(80{ }^{\circ} \mathrm{C}\right.$, buffer) was most effective from CS-ODN attached to functionalized MWCNT, whereas it was the least effective from CS-ODN attached to p-MWCNT. Furthermore, we could exemplarily demonstrate that AS-ODN hybridized to MWCNT-OH-bound CS-ODN could also be released at physiological settings $\left(37^{\circ} \mathrm{C}\right.$, urine). Taken together, MWCNT functionalized with hydrophilic moieties represent an interesting strategy for the intravesical treatment of $\mathrm{BCa}$ with therapeutic ASODN. Nevertheless, the mucoadhesive properties of MWCNT-based delivery systems and thus their dwell time at the urothelium have to be improved further possibly via coating or functionalization with hydrophilic polymers. 


\section{Additional file}

Additional file 1: Figure S1. (A) TGA curves, (B) FT-IR spectra and (C) Raman spectra of pristine and functionalized MWCNT. a.u.: arbitrary units; rel.: relative. Figure S2. Dispersibility and dispersion stability of pristine and functionalized MWCNT in PBS. Dispersions of MWCNT (1 mg/ $\mathrm{ml}$ ) were freshly prepared in PBS by sonication for $30 \mathrm{~min}$. Images were taken immediately after sonication ( $0 \mathrm{~h}$ ), after storing for $24 \mathrm{~h}$ at room temperature followed by soft agitation and after storing for another three months. Figure S3. Cytoplasmic localization of MWCNT-OH within EJ28 cells as visualized by TEM. Representative TEM images of EJ28 cells after incubation with $0.1 \mathrm{mg} / \mathrm{ml}$ MWCNT-OH for $24 \mathrm{~h}$ are depicted. The image in (B) represents a higher magnification of the area defined in (A). Black arrows indicate MWCNT inside the cells. Cy: cytoplasm; Ly: Iysosome; M: mitochondrion; $\mathrm{V}$ : vacuole.

\section{Abbreviations}

6-FAM: 6-carboxyfluorescein; AS-ODN: antisense oligodeoxynucleotides; a.u.: arbitrary units; BCa: bladder cancer; CNT: carbon nanotubes; CSODN: carrier strand oligodeoxynucleotides; Cy: cytoplasm; DCC: N,N'dicyclohexylcarbodiimide; DHBA: 3,4-dihydroxybenzaldehyde; DMEM: Dulbecco's modified eagle's medium; DMF: N,N-dimethylformamide; DSS: disuccinimidyl suberate; EDC: 1-ethyl-3-(3-dimethylaminopropyl)carbodiimid; FT-IR: Fourier transform infrared spectroscopy; HE: hematoxylin-eosin; Ly: Iysosome; M: mitochondrion; Mal: maleimide; MES: 2-(N-morpholino) ethanesulfonic acid; MWCNT: multi-walled carbon nanotubes; NHS: N-hydroxysuccinimid; NS-ODN: nonsense oligodeoxynucleotides; Nu: nucleus; ODN: oligodeoxynucleotides; PBS: phosphate buffered saline; p-MWCNT: pristine multi-walled carbon nanotubes; rel.: relative; RT: room temperature; siRNA: small interfering RNAs; SWCNT: single-walled carbon nanotubes; TEM: transmission electron microscopy; TGA: thermogravimetric analysis; THF: tetrahydrofuran; $\mathrm{V}$ : vacuole; XPS: X-ray photoelectron spectroscopy.

\section{Authors' contributions}

AK, SH, SF and BS designed and coordinated the study. SH, SF and BS contributed reagents, materials and analysis tools. AK, SH, CR, DK, DS and KE performed the experiments and analyzed the data. AK, SH, SF and KE drafted the manuscript. All authors read and approved the final manuscript.

\section{Author details}

${ }^{1}$ Chair of Biochemistry, Department of Chemistry, Technische Universität Dresden, Bergstraße 66, 01069 Dresden, Germany. ${ }^{2}$ Leibniz Institute for Solid State and Materials Research Dresden, Helmholtzstraße 20, 01069 Dresden, Germany. ${ }^{3}$ Department of Urology, University Hospital Carl Gustav Carus, Technische Universität Dresden, Fetscherstraße 74, 01307 Dresden, Germany. ${ }^{4}$ Present Address: Department of Nanostructured Materials, Leibniz Institute for Polymer Research, Hohe Straße 6, 01069 Dresden, Germany.

\section{Acknowledgements}

The authors are very grateful to Elke John and Brigitte Hamann for providing the mouse bladders and the TEM analysis of cellular uptake, respectively. We acknowledge support by the German Research Foundation and the Open Access Publication Funds of the TU Dresden.

\section{Competing interests}

The authors declare that they have no competing interests.

\section{Availability of data and additional materials section}

The datasets used and/or analyzed during the current study are available from the corresponding author on reasonable request.

\section{Funding}

This work was supported by the German Cancer Aid (Grant Number 109616). The funding body was not involved in the study design, data collection, analysis, interpretation, or writing of the manuscript.

\section{Publisher's Note}

Springer Nature remains neutral with regard to jurisdictional claims in published maps and institutional affiliations.

Received: 7 March 2017 Accepted: 8 July 2017

Published online: 17 July 2017

\section{References}

1. Babjuk M, Burger M, Zigeuner R, Shariat SF, van Rhijn BW, Comperat E, Sylvester RJ, Kaasinen E, Bohle A, Palou Redorta J, Roupret M, European Association of U. EAU guidelines on non-muscle-invasive urothelial carcinoma of the bladder: update 2013. Eur Urol. 2013;64:639-53.

2. Witjes JA, Comperat E, Cowan NC, van der Santis M, Gakis G, Lebret T, Ribal MJ, de Heijden AG, Sherif A, European Association of U. EAU guidelines on muscle-invasive and metastatic bladder cancer: summary of the 2013 guidelines. Eur Urol. 2014;65:778-92.

3. GuhaSarkar S, Banerjee R. Intravesical drug delivery: challenges, current status, opportunities and novel strategies. J Control Release. 2010;148:147-59.

4. Massari F, Santoni M, Ciccarese C, Brunelli M, Conti A, Santini D, Montironi R, Cascinu S, Tortora G. Emerging concepts on drug resistance in bladder cancer: implications for future strategies. Crit Rev Oncol Hematol. 2015;96:81-90.

5. Chandrasekar T, Evans CP. Autophagy and urothelial carcinoma of the bladder: a review. Investig Clin Urol. 2016;57(Suppl 1):S89-97.

6. Bates K, Kostarelos K. Carbon nanotubes as vectors for gene therapy: past achievements, present challenges and future goals. Adv Drug Deliv Rev. 2013;65:2023-33.

7. Kumar S, Rani R, Dilbaghi N, Tankeshwar K, Kim KH. Carbon nanotubes: a novel material for multifaceted applications in human healthcare. Chem Soc Rev. 2017:46:158-96.

8. Caoduro C, Hervouet E, Girard-Thernier C, Gharbi T, Boulahdour H, Delage-Mourroux R, Pudlo M. Carbon nanotubes as gene carriers: focus on internalization pathways related to functionalization and properties. Acta Biomater. 2017;49:36-44.

9. Arlt M, Haase D, Hampel S, Oswald S, Bachmatiuk A, Klingeler R, Schulze R, Ritschel M, Leonhardt A, Fuessel S, Buchner B, Kraemer K, Wirth MP. Delivery of carboplatin by carbon-based nano containers mediates increased cancer cell death. Nanotechnology. 2010;21:335101.

10. Hampel S, Kunze D, Haase D, Kramer K, Rauschenbach M, Ritschel M, Leonhardt A, Thomas J, Oswald S, Hoffmann V, Buchner B. Carbon nanotubes filled with a chemotherapeutic agent: a nanocarrier mediates inhibition of tumor cell growth. Nanomedicine (Lond). 2008;3:175-82.

11. Kaufmann A, Kunhardt D, Cirillo G, Hampel S, Schwenzer B. Functionalized carbon nanotubes as transporters for antisense oligodeoxynucleotides. J Mater Chem B. 2014;2:7000-8.

12. Crinelli R, Carloni E, Menotta M, Giacomini E, Bianchi M, Ambrosi G, Giorgi L, Magnani M. Oxidized ultrashort nanotubes as carbon scaffolds for the construction of cell-penetrating NF-kappaB decoy molecules. ACS Nano. 2010;4:2791-803.

13. Jia N, Lian Q, Shen H, Wang C, Li X, Yang Z. Intracellular delivery of quantum dots tagged antisense oligodeoxynucleotides by functionalized multiwalled carbon nanotubes. Nano Lett. 2007;7:2976-80.

14. Pan B, Cui D, Xu P, Ozkan C, Feng G, Ozkan M, Huang T, Chu B, Li Q, He $\mathrm{R}, \mathrm{Hu} \mathrm{G}$. Synthesis and characterization of polyamidoamine dendrimercoated multi-walled carbon nanotubes and their application in gene delivery systems. Nanotechnology. 2009;20:125101.

15. Rieger C, Kunhardt D, Kaufmann A, Schendel D, Huebner D, Erdmann K, Propping S, Wirth MP, Schwenzer B, Fuessel S, Hampel S. Characterization of different carbon nanotubes for the development of a mucoadhesive drug delivery system for intravesical treatment of bladder cancer. Int $J$ Pharm. 2015:479:357-63.

16. Ringel J, Erdmann K, Hampel S, Kraemer K, Maier D, Arlt M, Kunze D, Wirth MP, Fuessel S. Carbon nanofibers and carbon nanotubes sensitize prostate and bladder cancer cells to platinum-based chemotherapeutics. J Biomed Nanotechnol. 2014;10:463-77. 
17. Ritschel M, Leonhardt A, Elefant D, Oswald S, Büchner B. Rhenium-catalyzed growth carbon nanotubes. J Phys Chem C. 2007;111:8414-7.

18. Jeong YN, Choi MY, Choi HC. Preparation of Pt- and Pd-decorated CNTs by DCC-activated amidation and investigation of their electrocatalytic activities. Electrochim Acta. 2012;60:78-84.

19. Forster Y, Meye A, Krause S, Schwenzer B. Antisense-mediated VEGF suppression in bladder and breast cancer cells. Cancer Lett. 2004;212:95-103.

20. Karachevtsev MV, Gladchenko GO, Plokhotnichenko AM, Leontiev VS, Karachevtsev VA. Adsorption of biopolymers on SWCNT: ordered poly $(\mathrm{rC})$ and disordered poly(rl). J Phys Chem B. 2013;117:2636-44.

21. Johnston HJ, Hutchison GR, Christensen FM, Peters S, Hankin S, Aschberger K, Stone V. A critical review of the biological mechanisms underlying the in vivo and in vitro toxicity of carbon nanotubes: the contribution of physico-chemical characteristics. Nanotoxicology. 2010;4:207-46.

22. Zhang T, Tang M, Kong L, Li H, Zhang T, Zhang S, Xue Y, Pu Y. Comparison of cytotoxic and inflammatory responses of pristine and functionalized multi-walled carbon nanotubes in RAW 264.7 mouse macrophages. J Hazard Mater. 2012;219-220:203-12.

23. Ursini CL, Maiello R, Ciervo A, Fresegna AM, Buresti G, Superti F, Marchetti M, lavicoli S, Cavallo D. Evaluation of uptake, cytotoxicity and inflammatory effects in respiratory cells exposed to pristine and $-\mathrm{OH}$ and - $\mathrm{COOH}$ functionalized multi-wall carbon nanotubes. J Appl Toxicol. 2016;36:394-403.

24. Saxena RK, Williams W, McGee JK, Daniels MJ, Boykin E, lan Gilmour M. Enhanced in vitro and in vivo toxicity of poly-dispersed acid-functionalized single-wall carbon nanotubes. Nanotoxicology. 2007;1:291-300.

25. Patlolla A, Patlolla B, Tchounwou P. Evaluation of cell viability, DNA damage, and cell death in normal human dermal fibroblast cells induced by functionalized multiwalled carbon nanotube. Mol Cell Biochem. 2010;338:225-32.

26. Muller J, Huaux F, Fonseca A, Nagy JB, Moreau N, Delos M, Raymundo-Pinero E, Beguin F, Kirsch-Volders M, Fenoglio I, Fubini B, Lison D. Structural defects play a major role in the acute lung toxicity of multiwall carbon nanotubes: toxicological aspects. Chem Res Toxicol. 2008;21:1698-705.

27. Karimi M, Solati N, Ghasemi A, Estiar MA, Hashemkhani M, Kiani P, Mohamed E, Saeidi A, Taheri M, Avci P, Aref AR, Amiri M, Baniasadi F, Hamblin MR. Carbon nanotubes part II: a remarkable carrier for drug and gene delivery. Expert Opin Drug Deliv. 2015;12:1089-105.

28. Barthelmes J, Dunnhaupt S, Unterhofer S, Perera G, Schlocker W, BernkopSchnurch A. Thiolated particles as effective intravesical drug delivery systems for treatment of bladder-related diseases. Nanomedicine (Lond). 2013;8:65-75.
29. Barthelmes J, Perera G, Hombach J, Dunnhaupt S, Bernkop-Schnurch A. Development of a mucoadhesive nanoparticulate drug delivery system for a targeted drug release in the bladder. Int J Pharm. 2011;416:339-45.

30. Huang C, Neoh KG, Xu L, Kang ET, Chiong E. Polymeric nanoparticles with encapsulated superparamagnetic iron oxide and conjugated cisplatin for potential bladder cancer therapy. Biomacromol. 2012;13:2513-20.

31. Zhang Q, Neoh KG, Xu L, Lu S, Kang ET, Mahendran R, Chiong E. Functionalized mesoporous silica nanoparticles with mucoadhesive and sustained drug release properties for potential bladder cancer therapy. Langmuir. 2014;30:6151-61.

32. Lu S, Xu L, Kang ET, Mahendran R, Chiong E, Neoh KG. Co-delivery of peptide-modified cisplatin and doxorubicin via mucoadhesive nanocapsules for potential synergistic intravesical chemotherapy of non-muscleinvasive bladder cancer. Eur J Pharm Sci. 2016;84:103-15.

33. Mun EA, Williams AC, Khutoryanskiy WV. Adhesion of thiolated silica nanoparticles to urinary bladder mucosa: effects of PEGylation, thiol content and particle size. Int J Pharm. 2016;512:32-8.

34. Storha A, Mun EA, Khutoryanskiy V. Synthesis of thiolated and acrylated nanoparticles using thiol-ene click chemistry: towards novel mucoadhesive materials for drug delivery. Rsc Adv. 2013;3:12275-9.

35. Denora N, Lopedota A, Perrone M, Laquintana V, lacobazzi RM, Milella A, Fanizza E, Depalo N, Cutrignelli A, Lopalco A, Franco M. Spray-dried mucoadhesives for intravesical drug delivery using $\mathrm{N}$-acetylcysteine- and glutathione-glycol chitosan conjugates. Acta Biomater. 2016:43:170-84.

36. Cirillo G, Hampel S, Spizzirri UG, Parisi OI, Picci N, lemma F. Carbon nanotubes hybrid hydrogels in drug delivery: a perspective review. Biomed Res Int. 2014;2014:825017.

37. Nordstrom LJ, Clark CA, Andersen B, Champlin SM, Schwinefus JJ. Effect of ethylene glycol, urea, and $\mathrm{N}$-methylated glycines on DNA thermal stability: the role of DNA base pair composition and hydration. Biochemistry. 2006:45:9604-14

38. Fuessel S, Kueppers B, Ning S, Kotzsch M, Kraemer K, Schmidt U, Meye A, Wirth MP. Systematic in vitro evaluation of survivin directed antisense oligodeoxynucleotides in bladder cancer cells. J Urol. 2004;171:2471-6.

39. Kraemer K, Fuessel S, Schmidt U, Kotzsch M, Schwenzer B, Wirth MP, Meye A. Antisense-mediated hTERT inhibition specifically reduces the growth of human bladder cancer cells. Clin Cancer Res. 2003;9:3794-800.

\section{Submit your next manuscript to BioMed Central and we will help you at every step:}

- We accept pre-submission inquiries

- Our selector tool helps you to find the most relevant journal

- We provide round the clock customer support

- Convenient online submission

- Thorough peer review

- Inclusion in PubMed and all major indexing services

- Maximum visibility for your research

Submit your manuscript at www.biomedcentral.com/submit
BioMed Central 